\title{
Review on Environmental Treatment of Heavy Pollution Industry
}

\author{
Jing Chen ${ }^{1,2}$, Xiaoxue $\mathrm{Mu}^{3}$ \\ ${ }^{1}$ Nanjing Vocational Institute of Transport Technology, Nanjing, China \\ ${ }^{2}$ Jiangsu Engineering Technology Research Center for Energy Conservation and Emission Reduction of Transportation, Nanjing, China \\ ${ }^{3}$ Business School, Hohai University, Nanjing, China
}

\begin{abstract}
The development of heavy pollution industry has a certain impact on the ecological environment. This paper combs and summarizes the environmental treatment technology of heavy pollution industry from the aspects of air pollution and water pollution. During studing the advantages and disadvantages of various environmental treatment technologies, the authors finds that there are the following problems in the development of environmental treatment technology of heavy pollution industry in China: there is a lack of long-term planning for air pollution environmental treatment; The cost of water pollution control is high and the energy consumption is large. Therefore, relevant environmental governance departments should promote the concept of sustainable development and strengthen the constraints of waste gas and sewage treatment process; Enterprises in heavy pollution industries need to learn and learn from the cutting-edge technologies of environmental governance; Social media positively guide enterprises in heavily polluting industries to protect the ecological environment through public supervision.
\end{abstract}

\section{Introduction}

In recent years, the status of heavy pollution industry in China's economic development is increasing day by day, but at the same time, a series of ecological and environmental problems brought by the development of heavy pollution industry can not be ignored. Among them, sewage discharge, global warming, dust storms and haze seriously threaten the natural environment on which human beings depend. The disharmony between the development of heavily polluting enterprises and environmental protection is the main contradiction in China's environmental governance. Only by developing green economy and promoting environmental governance can we fundamentally solve this problem. General Secretary Xi stressed that "green water and green mountains are golden mountains and silver mountains". At present, economic and social development should not only focus on immediate interests, but also concentrate on the sustainable development of future generations. China has entered a new stage of ecological civilization construction, and the environmental management of heavy pollution industry is imminent.

By using the literature research method, this paper comprehensively and deeply did research on the specific application of environmental treatment technology in heavy pollution industry from the aspects of the connotation of heavy pollution industry, the treatment technology and development prospect of air pollution and water pollution. Meanwhile, this study explored the weaknesses of existing research and places for optimization, striving to get suggestions and countermeasures for improving the development of environmental treatment technology in China's heavy pollution industry.

\section{Research trends of environmental governance in heavy pollution industry}

In 1962, American writer Rachel Carson published a wake-up masterpiece called silent spring, which triggered people's thinking on ecological and environmental problems, and the seriousness of environmental pollution had been displayed in front of people all over the world[1]. This study studied the characteristics and advantages of pollution control technology in relevant fields by sorting out the relevant technical documents of environmental treatment in heavy pollution industries at home and abroad, in order to provide a reliable basis for environmental treatment in heavy pollution industries in China in the future.

\subsection{Research on the connotation of heavy pollution industry}

There is no unified standard for the definition of heavy pollution industry in academia. Combing the literature of foreign scholars, it is found that the concept of "heavily polluting industry" rarely appears, but the common words are "dirty" industry or pollution intensive industry. Some domestic scholars choose the research object of "heavy pollution industry" based on the division standards stipulated by relevant national departments. The existing literature usually determines which industries belong to "heavy pollution industries" according to the standards 
such as pollution emission intensity, high and low pollution control cost, pollutant emission and the proportion of wastewater and waste gas emission in the overall industrial emission. The guidance on industry classification of listed companies revised by the CSRC in 2012 had further adjusted and standardized 16 heavily polluting industries on the basis of the division of the Ministry of environmental protection. Heavy pollution industries are divided into $16 \mathrm{sub}$ industries, including thermal power, steel and cement. Its impact mainly includes air pollution and water pollution.

\subsection{Research progress of environmental treatment technology in heavy pollution industry}

(1) Air pollution and environmental control technology Air pollution is not just gas pollution. Strictly speaking, air pollution is divided into particulate pollution, gaseous pollution and radioactive pollution[2]. Among them, the air pollutants emitted from the combustion of ore bodies and fuels in heavy industry are one of the main sources of air pollution. Bolen[3] found through research that modern pollution control measures had been adopted in particle plants in Sweden and the United States circulating fluidized bed with sulfur control, electrostatic precipitator or bag filter with activated carbon and particles in the process of iron ore hardening or pelletization. Liu Huajun and Qiao Liecheng[4] collected the daily ground monitoring data of PM2.5 in Central European cities from 2017 to 2019 by using the pathon technology, quantified the spatial interaction degree of air pollution between China and Europe by using the big data transfer entropy method, and revealed the spatial network structure of the interaction of air pollution between China and Europe from the network perspective. Then they put forward targeted policy suggestions for China EU bilateral cooperation in air pollution control. The identification study of woody biomass samples found that southwest Nigeria had the ability to start large-scale production of these woody organisms. The vigorous investment in the reproduction of these energy crops would promote the use of woody blocks as raw materials for the sustainability of power supply in thermal power plants[5]. These woody fuels brought less air pollutants in the combustion process than traditional fuels, so as to reduce environmental pollution. Zhang Xiao et al.[6] prepared Mn/MCM-41 and IMp-Mn/MCM-41 catalysts by using metal heteroatom substitution and impregnation method, studied the catalytic oxidation performance of toluene in dielectric barrier non thermal plasma (NTP) reactor, and optimized the stability of the catalyst and the parameters of catalytic oxidation conditions. The characterization showed that the catalytic oxidation of toluene in air could be accelerated by the incorporation of manganese into the catalyst in a non thermal plasma system.

The development of heavy industry has brought a lot of air pollution, and coal combustion has brought a lot of sulfur dioxide pollution, especially in the case of serious haze in China, there are more and more inhalable particles and a large number of fine pollutants, which are easy to cause harm to people [7]. Guo Yi [8] studied the technical transformation of boiler dismantling and grid connection and the prevention and control of air pollution, dismantled small coal-fired boilers and incorporated them into large capacity boilers or thermal power plants. Thus, it improved the infrastructure of urban gas for central heating, strengthened the remediation of smoke and dust pollution, and improved the urban greening coverage, so as to achieve environmental protection and emission reduction. Shang Huihui[9] proposed that sulfur dioxide pollution can be reduced through coal desulfurization treatment, that is, coal biological desulfurization technology. Bioleaching used the catalytic enzymes and life activities in microbial strains to release the sulfur in coal. It is a common desulfurization technology. The coal purification technology also belongs to the treatment of pollution. It will greatly reduce the emission of sulfur dioxide in China and effectively alleviate the pressure of air pollution control in China.

(2) Water resources pollution and environmental treatment technology

Wastewater from heavily polluted industries contains organic and inorganic pollutants. Environmental treatment technologies of water resources pollution mainly include biological method, physical method, chemical method and other treatment technologies [10]. In order to study the efficiency of heavy metal adsorbent in industrial wastewater, elboughdiri [11] studied the adsorption behavior of natural zeolite on $\mathrm{Cu}$ ions, $\mathrm{Pb}$ ions and $\mathrm{Cd}$ ions in synthetic metal solution. The research showed that zeolite was suitable for removing $\mathrm{Cu}, \mathrm{Pb}$ and $\mathrm{Cd}$ ions from synthetic wastewater; It is found that the quality of adsorbent, initial solution concentration, initial solution $\mathrm{pH}$, adsorbent particle size and stirring speed affect the removal efficiency of heavy metals in natural zeolite industrial wastewater. Dyes and heavy metals pose a serious threat to drinking water. These pollutants may be harmful or carcinogenic in nature and harmful to humans and different aquatic species. Therefore, it is of great significance to remove heavy metals and dyes and reduce their environmental toxicity.

Domestic scholar Jiang Ting [12] proposed to adopt environmental chemistry technology to treat the pollution of wastewater, waste gas and waste residue. In the process of wastewater treatment, the most widely used ultrafiltration technology is to separate and concentrate wastewater by using microporous aluminum membrane. This technology has the characteristics of high efficiency and high quality. Environmental chemistry technology has great advantages in environmental treatment. Its treatment cycle is short and the investment cost is low. The incidence of secondary pollution is reduced, so the pollution source can be effectively controlled with the result that the pollution treatment effect is greatly improved, and the efficiency and quality of environmental treatment are improved. 


\section{Problems of environmental treatment technology in heavy pollution industry}

(1) Lack of long-term planning for air pollution and environmental control

Reducing pollutant emissions and controlling pollution sources are the main breakthroughs of air pollution and environmental treatment technology. The aggravation of environmental pollution has a direct impact on China's air quality. The government has achieved good results in short-term environmental pollution control through effective haze control measures such as "dust reduction, coal pressure and greening". The environmental governance of heavy pollution industry should promote each other with economic development, but the long-term planning of environmental governance of heavy pollution industry lacks dynamic mechanism and long-term governance planning of sustainable development, resulting in the opposition between environmental governance and economic development. Air pollution control technology needs to be further improved. It is necessary to speed up the development of air pollution control technology from the long-term interests of ecological and environmental protection.

(2) High cost and energy consumption of water pollution and environmental treatment

When carrying out water pollution control, we should scientifically select various ecological restoration technologies, such as biofilm technology, microbial remediation technology and aquatic vegetation restoration technology, according to the requirements of relevant specifications and in combination with the actual situation of water pollution type, pollution scope and pollution degree in order to control and protect the water environment, then promote the sustainable and healthy development of the water environment[13]. Although this kind of efficient and friendly microbial enhancement technology which helps to protect the ecological environment has high application value, it also has defects such as high cost and high energy consumption. Enterprises may abandon this technology because they are unable to pay high fees in sewage treatment, resulting in increased environmental pollution.

\section{Analysis on improvement countermeasures of environmental treatment technology in China's heavy pollution industry}

\subsection{Government level}

Relevant environmental treatment department shall, in accordance with the concept of environmental sustainable development advocated by the state and in combination with relevant schedule planning, reasonably arrange the pollution treatment of heavy polluting industries, make internal management orderly, and conduct effective research on the environmental treatment of foreign heavy polluting industries. The government should actively learn from relevant experience and optimize the governance scheme to make it more in line with the actual situation. In addition, we should standardize the order of the national environmental market, strengthen the constraints of relevant systems on relevant waste gas and sewage treatment managers. And the department should severely crack down on the adverse phenomenon of paying attention to interests and ignoring the effect of sewage treatment in carrying out specific work. In view of the unqualified sewage discharged by industrial production enterprises, the government should do a good job in management to promote the rational operation of sewage treatment of industrial enterprises abiding by the national sewage treatment system and rigid regulations.

\subsection{Companies level}

The development of enterprise treatment technology in heavy pollution industry needs to start from itself, improve the level of technical development, and apply it to promote the improvement of environmental pollution treatment capacity and efficiency of China's heavy pollution industry. In terms of technological innovation, enterprises should actively introduce advanced high-end technology; At the same time, strive to go global, actively grasp the technical learning opportunities of heavy pollution industry and environmental treatment industry, learn skills in communication and exchange, and improve the pollution of air and water waste in China ${ }^{[14]}$.

\subsection{Social dimension}

The public also plays an important role in the process of environmental governance of heavy pollution industries. The media can strengthen the effective supervision of public opinion, release relevant public opinion through multiple channels such as the Internet, and positively guide enterprises in heavy pollution industries to actively protect the ecological environment and bear the main responsibility of environmental governance. People should actively support environmental protection industries, consume less or do not consume enterprise products with high energy consumption. They should try hard to reduce environmental pollution caused by heavy polluting enterprises with high consumption and high pollution, and promote the development of environmental treatment technology in heavy polluting industries as a result of further promoting the vigorous development of economy and society.

\section{Conclusions}

On the basis of combing the environmental treatment technologies of heavy pollution industries at home and abroad, this paper studies the environmental treatment technologies of heavy pollution industries from the aspects of air pollution and water pollution; Based on the relevant research at home and abroad, this paper summarizes the advantages and disadvantages of the current development of environmental treatment technology in heavy pollution industry, and puts forward 
the environmental treatment countermeasures and suggestions suitable for China's national conditions.

\section{Acknowledgments}

This work was financially supported by Self financing project of Jiangsu Social Science Foundation (Grant No. 20GLD009).

\section{References}

1. He Ke, Zhang Junbiao, Zhang Lu, Wu Xuelian. Interpersonal trust, institutional trust and farmers' willingness to participate in Environmental Governance-Taking the recycling of agricultural waste as an example [J]. Management world, 2015 (05): 75-88

2. Hao Yiren, Meng Chao, Liu kunkun. Analysis on the development of industrial air pollution control technology [J]. China's comprehensive utilization of resources, 2020,38(06): 132-134

3. Bolen, J. Modern air pollution control for iron ore induration[J]. Minerals \& Metallurgical Processing, 2014,31(2).

4. Liu Huajun, Qiao Liecheng. Spatial interaction network of air pollution between China and Europe and bilateral cooperative governance -- An Empirical Study Based on big data causal inference technology [J]. Statistical research, 2021,38 (02): 45-56

5. F. B. Elehinafe et al. Identification of the woody biomasses in Southwest, Nigeria as potential energy feedstocks in thermal power plants for air pollution control[J]. Cogent Engineering, 2021, 8(1)

6. Zhang Xiao et al. Catalytic oxidation of toluene in air using manganese incorporated catalyst by nonthermal plasma system[J]. Separation and Purification Technology, 2021, 257

7. Shang Huihui. Application of environmental chemistry technology in environmental pollution control [J]. Chemical design communication, 2019, 45 (09): $236+238$

8. Guo Yi. Technical transformation of boiler dismantling and grid connection and control of air pollution $[\mathrm{J}]$. Chemical engineering and equipment, 2020 (11): 280-281+291

9. Shang Huihui. Application of environmental chemistry technology in environmental pollution control [J]. Chemical design communication, 2019, 45 (09): 236-238

10. Men Yonghong, Chen Xiujin, Du Yu, Xu Xuemi. Problems and solutions in industrial sewage treatment in environmental engineering [J]. Management and science and technology of small and medium-sized enterprises (next ten days), 2021 (04): 61-62

11. Noureddine Elboughdiri and Harvey Arellano Garcia. The use of natural zeolite to remove heavy metals $\mathrm{Cu}$
(II), $\mathrm{Pb}$ (II) and $\mathrm{Cd}$ (II), from industrial wastewater[J]. Cogent Engineering, 2020, 7(1)

12. Jiang Ting, Zhu Huijun, Yan Chao, Han Rongrong. Application of environmental chemistry technology in environmental pollution control and protection [J]. Biochemical industry, 2019,5 (02): 117-119

13. Ma Ji. Application of bioremediation technology in water pollution control $[\mathrm{J}]$. Comprehensive utilization of resources in China, 2021,39 (04): 192194

14. Liu Jiaming. Study on the path of environmental transformation and upgrading of China's heavy pollution industry [D]. Beijing University of chemical technology, 2020 